\title{
Role of Philosophy of Education in India
}

\author{
Kiran Srivastava *
}

\section{Abstract}

One of the important aspects of educational philosophy is that it helps to construct a comprehensive system of education. During different periods, India has witnessed various stages of development. New priorities have emerged in education with the influences of monastic scholastic, realistic, idealistic and pragmatic trends. While education institutions have evolved, there remain several gaps between the philosophical ideals proposed by educational institutions and their everyday functioning. The paper brings forth the urgent need to bridge the gaps in order to attain a comprehensive philosophy of education, in principle and in action. The authors posit that the Indian philosophy of education, normatively speaking, could extend the culture and tradition of the philosophical positions of Mahatma Gandhi, Rabindranath Tagore, Sri Aurobindo and Swami Vivekananda. Such an approach could help in developing an integrated approach of teachers towards education and assist in strengthening their role in shaping the inner potential of a learner in a constructive manner.

Keywords: Indian Educational Philosophy, Mahatma Gandhi, Rabindranath Tagore, Sri Aurobindo, Swami Vivekananda

*Central University of Jharkhand, India; ksrivastava5@gmail.com 


\section{Introduction}

The landscape of Indian education system has witnessed fundamental structural transformation during the post Independence period both quantitatively and qualitatively. In today's Globalization Era, knowledge is increasingly a commodity that moves between the nations and people. Nevertheless, the attainment of philosophical education contributes significantly to establish a set of values and qualities to individuals (Kumara, 2016). While the growth of knowledge based philosophical analyses varies from one academic setting, or school of thought or socio cultural context to another, the education system plays a crucial role in establishing a nation's ability to succeed in the modern global scenario of educational philosophy.

With this perspective, the present paper attempts to examine the issues of educational philosophy in India. It addresses the different perspectives of philosophers from pre-independence to postindependence era. Different sources of philosophical ideas of education highlights the changes in terms of incorporating the integrated approach of teachers in shaping the inner potential of a learner through the development of content and of the philosophy of teaching.

\section{Background of Indian educational philosophy}

The salient features of Indian philosophy of life and thought are based on the quest for spiritual values which stresses upon the unity of existence, the divinity of man and harmony of creeds and religions. On the other hand, western traditions of educational philosophy stresses upon the pragmatic view of life to measure the value of the man in accordance to his/her utility in the society (Dupuis \& Gordon, 2010). Indian philosophy of education gives importance to the essence of creating a sense of universal humanhood and spirituality. Tagore reiterates in his philosophy of education, the need to evolve the pattern of life encapsulated by the realisation of the sense of universal humanhood.

In order to face the changes in the modern world and adapt to the educational needs of the learner in the twenty-first century, Indian philosophy of education needs to maintain a proper balance 
between the past and the present to prepare the learners for the future and orient them towards the need to celebrate the diversity in social and cultural traditions (Sahan \& Terzi, 2015). The educational institution has to take a constructive role to maintain the inter-linkages between science, spirituality and technology (Kumara, 2016).

\section{Indian educational philosophy}

India, like all other nations has been influenced by diverse educational philosophies because of the historical transformations of societies, influx of heterogeneous ideas from various communities, both from India and from outside of the Indian context.

The Vedic period of Indian education stressed upon the holistic prosperity and spiritual well-being of a human, wherein the philosophical and metaphysical aspects of the divinity of mankind is acknowledged. During this period, learning was sought as the means to the highest end of life - the attainment of emancipation or Mukti, often considered as an essential aspect of Hindu religious discourses.

However, there were alternative perspectives which stressed on the fact that education should be related to the development of moral character rather than considered as an exclusive means of attaining scripture based intellectual capabilities (Sharma, 2003). Buddhism, for example, in the Indian context, considered it important to understand the cosmic sense of salvation. Indian educational philosophies and by extension, their expression as university spaces were acknowledged globally, for example, during the Buddhist era, universities and education system had the privilege to get universal fame (Chakrabarti, 1995). In the next few sections, the article will aim to lay out specific features of the trends in educational philosophies in broad historical periods, followed by educational philosophies of a few iconic educators.

\section{Vedic period}

In the educational philosophy of ancient India, respect for the teacher was considered to be of supreme importance. The teacher, who imparted the knowledge of Vedas was considered as a pivot 
of the whole educational system. Within Vedic educational philosophy, attainment of Moksha or liberation was of utmost importance. The educational philosophy in Upanishad is more closely tied to the social and cultural traditions. It emphasised on the all round development of a person, prioritising the development of personality and character, accountability towards national integration, knowledge of social roles and status and development of one's vocational efficiency. The pedagogic methods involved included questioning, induction and deduction, discussion, descriptions, illustrations, practical and narratives demonstration.

Within the social fabric of the four-fold Ashramas or life stages (Brahmacharya, Garhastya, Vanaprastha and Sannyasa) of the student, the educational philosophy in Vedic period was influenced by the stages to attain Moksha or Liberation. The basic purpose of education, it was stressed, does not end with the education of the students at the first stage but it should help them move towards the other stages of life. It should help the individual to understand the processes to engage in self-realisation by unfolding the spiritual realm within them (Sharma, 2003).

\section{Medieval period}

Medieval period witnessed strong influences of Jainism, Buddhism and Islam in the educational transformations. Based on core principles such as non-violence and the law of Karma, these schools, albeit with differences in their epistemic, ontological and metaphysical realities spoke of the ultimate goal of liberation, that is, the emancipation from the cycle of death and birth. The emphasis was laid on four noble truths (aryasatyas) as the ultimate goal of education: the linkages between the world, life and libreraton were explained as the following. The world is full of miseries (dukha) and the cause of miseries is ignorance (sukhasamudaya). Cessation of miseries (dukhanirodha) is important to achieve liberation and the learner should be aware of the ways to get rid of miseries (dukha-nirodh-marg). Jainism and Buddhism aspired, to a large extent to personify an individual God, provide greater assertion on morality, the aspirations of the 
common man and offer rational interpretations of the meanings of human life (Kumara, 2016).

The educational philosophy that was derived from the Islamic education system aimed to understand discourses from the Quran and sought to bring into focus, the development of practical skill for the cultural, economic and social cohesion. There was an attempt to balance scriptural knowledge and attainment of vocational expertise. An emphasis on learning agriculture, arts, medicine and various types of crafts and house building were an essential part of the curriculum. Military science, incidentally was also an important part of the curriculum. Depending on the governance and location of the school and its principles, the medium of instruction varied, though in most contexts, medium of instructions in Tols was Sanskrit or regional languages, whereas in Madrassas, it was Arabic and Parsi. Several documents reveal that a typical syllabus from a medieval institutions would include subjects as diverse as philosophy, mathematics, logic, literature, history, geography, medicine, agriculture, grammar to name a few included under their gambit. In terms of focus areas, developing reading, writing and arithmetic were of importance (Bhatia, 1992).

\section{Modern period}

The Modern education system started under the British rule. Lord Macaulay introduced western educational philosophy in India. The educational views of Macaulay gave importance to the propagation of European literature and science, and this, eventually led to the neglect of vernacular Indian literature and the arts (Viswanathan, 1989). The British administrators and pedagogues in Europe prescribed and controlled the entire education system in India. Many scholars opine that the British educational system initiated a political and social awareness in the country. It also developed the cultural and literary consciousness for the nation. This education system had a dual purpose: it strengthened the foundations of the colonial superpower, that is, British rule and reinforced the theological and philosophical tenets of Christianity (Bhatia, 1992). Several scholars have critiqued the British philosophy of education, considering it to be against national interest. 
While we laid out, in quite schematic fashion, the several changes and influences that Indian educational philosophy surpassed, I now turn towards a few specific pedagogues who had a key role in shaping a distinct sense of Indian philosophy of education. These philosophers of education attempted to reconstruct the ideals, educational values, rebridge the cleavages between philosophies, culture and Indian education system as an alternative educational approach.

\section{Indian educational philosopher}

\section{Mahatma Gandhi}

Mahatma Gandhi experimented with the ideas of education and schooling through the establishment of Kocharab Ashrams, which posited that for a sound educational philosophy one needs a harmony of intellect, labour and passion. Gandhian philosophy stressed on the simplicity in language, literature and life. Gandhian thinking aimed to synthesise the value of svadharma and swadesi and the world of internationalism and brotherhood in the same field (Bhatia, 1992).

Education, he would often assert, has to emphasise the needs of the society. It has to be free, compulsory and universal, it has to give importance towards learning of craft, and it has to be delivered in the mother tongue. Moreover, he added that education has to inculcate the dignity of labour as the need of the hour and develop a sense of spirituality in the learner's life. Education has to contribute towards the reformation of the economy of the country, ensure national integrity and help build cohesion and solidarity in the society.

\section{Rabindranath Tagore}

Tagore's experimentation resulted in a unique sense of educational philosophy: the belief in unity in humanity. Rabindranath Tagore established Santiniketan with several objectives towards understanding citizenship, connections between man, nature and education and so forth. However, this later grew as a spiritual centre to change the inner life of participants. Rabindranath Tagore's ideals of educational philosophy resonates the harmony of the diverse facets of life, including, educational, cultural, artistic, 
political, social and intellectual. Tagore's philosophy aims to develop the spiritual as well as the physical growth of the learner as he believed that the manifestation of personality depends upon the self-realisation, spiritual knowledge and health of an individual. Education, he asserted, teaches people to realise the oneness of the globe and establish a universal brotherhood and based on intercultural understanding. In Tagore's humanism, the need of co-relation between man and nature is essential for ensuring peace and justice. He also asserted that since language expresses people's expression so it is essential that the medium of instruction be in mother tongue for the children's education.

Tagore gave importance on spiritual and moral education rather than on scriptural knowledge for an integral development of a human. He considered cooperation, selfless activities, love towards fellows and a responsibility towards nurturing social relationships to be the main purpose of one's informed mind. It, he argued, enabled the individual to live as a worthy being (Bhattacharjee, 2014).

\section{Sri Aurobindo}

Sri Aurobindo's experimentation sought to develop an integral man. Sri Aurobindo's educational philosophy considered five principle aspects of human life as important: the vital, the physical, the psychic and the spiritual. All these elements are complimentary and need to be nurtured until the end of life. The scheme of education, according to him, has two integral senses as it is simultaneously an integral part of five aspects of the individual being and is also integral for the nation and to the humanity.

The educational philosophy of Sri Aurobindo is based on the evolution of the idea of 'total humanity' with the emphasis placed on the principles of growth in unity that maintains the evolution of diversity. The education system that he proposed would prepare people as an individual through educating the person as a human being and as a member of a nation. It also gives importance to moral responsibilities of individuals to transcend narrower interests to wider ones. The circles of moral responsibility and loyalties proceed from wider to narrower and vice-versa. The man has to develop first as a human being, then as a citizen and finally 
as an individual. Most of the present confusion of values is due to an inversion of this order, he had asserted.

The integral education that he subscribed for can be attained by strengthening the five principles such as physical, vital, psychic, mental and spiritual aspects and it has to be developed together. The school cannot be isolated from the society, as it needs to develop the capacity of collaboration, silence and consultation. It has to be embedded in social systems, engaging and contributing to them whenever required. His philosophy provided a way to revisit opportunities that a curriculum can provide for discovering the powers of the mind, power and spirit of the students and learners (Kumara, 2016).

\section{Swami Vivekananda}

The educational philosophy of Swami Vivekananda considers education to be a powerful instrument of social change. Education is the continuous process of "the manifestation of perfection that is already in man". It covers all the aspects of life such as intellectual, physical, material, emotional, spiritual and moral and it can remove the major evils as priest-craft, ignorance, poverty and tyranny of the wise.

The foundation of the philosophy of education in India is in its cultural context that strengthens the political and social strength of the nation. The educational thought of Swami Vivekananda has much significance to the modern education system which has lost its connection with the values of human life. The education system now emphasises on rote learning without paying attention to a reformation of the mind. There is a need to remove the obstacles and provide all the necessary opportunities to students so that they develop an understanding of concentration to acquire knowledge. True education, he added, contributes to the nation and should not be restricted by individual ambitions (Banerjee \& M. M., 2015).

\section{Major challenges of educational philosophy}

The educational philosophy traced so far provides a foundation for the intellectual debate and dialogue that could deepen the understanding of educational philosophy and practice in the current context of India. The current education system in India is 
unable to address the learner's interest and be relevant to the learner and the educational values he/she needs to inculcate in the fast changing world (Griffiths, 2014; Hayden, 2012). It focuses only on employment and creates the obsession to memorise, rote learn and pass the examinations. This is a crucial time to look at the educational philosophies of great Indian philosophers and reexamine their educational thoughts and ideas for their relevance today. There is a need for an education system which not only nurtures the learner's souls with knowledge but also gives importance to instil a sense of sympathy for others. Additionally, it needs to help students move towards self-improvement and personal fulfilment (Bhattacharjee, 2014).

It is in this context, I argue, that there is a need for the universities to have a deeper understanding of the educational theory and practice of Indian educational philosophers to provide the needed perspective for intellectual dialogues. There is also a lack of quality, clarity and rigour to promote the consistency and semantic meaningfulness of our educational philosophies. Coupled with a lack of scholarly research as well as the perspective for an informed debate in the field of educational philosophy, there is a conspicuous absence of communication between 'pure' philosophers and philosophers of education, which has proved to be detrimental for its growth. Specifically, this gap has led to the failure in making education of today relevant, contemporary and yet rooted in our local contexts.

\section{Implication of the study}

The paper aims to the present education system which not only neglects the spiritual values but also fails to provide an adequate training for the mind. Plethora of indiscriminate information is forced on students, which fails to stimulate the thinking process. The educational philosophies of Indian educational philosophers, Rabindranath Tagore, Mahatma Gandhi, Swami Vivekananda and Sri Aurobindo are only taught in the classrooms but they are not transferred to students; values such as cutivation of humanity, morality and tolerance therefore, remains locked as unfulfilled promises within the scriptures as promising philosophical doctrines (Banerjee \& M. M. 2015; Bhattacharjee, 2014). 
It is important, at this juncture, to weave the basic principles of an educational philosophical framework as posited by these abovementioned educators. Taking the commonalities across these philosophers, we would observe that they argued for an education system that is effective in establishing equality, secularism and primacy of knowledge. They had also asserted that there is a need to engage with the rural society to bridge the gap between citizens of a state. They envisioned that the role of education is to develop creativity, skills and make students self reliant, conscious and situated in a local context. This, they thought would build the democratic fervour of the nation and strengthen its secular fabric, the achievement of which, we had pledged in the constitution.

To contribute to the democratic social transformation of the society, this paper proposes, the need to prepare a national educational framework that develops and encourages an integrated approach towards educational philosophy. The Indian education system has the responsibility to prepare the future learners to understand the value of culture and tradition, which when coupled with this framework, should pledge to instill a democratic vision, scientific temper and need for just and tolerant society in all students and learners.

\section{References}

Banerjee, A. K., \& Mahi. M. (2015). Educational philosophy of Swami Vivekananda. International Journal of Educational Research and Development,4(3), 030-035.

Bhatia, K. (1992). The Philosophical and Sociological Foundations of Education.

Bhattacharjee, S. (2014). Relevance of Tagore's philosophy of education in postmodern era-a conceptual analysis. OSR Journal of Humanities and Social Science (IOSR-JHSS) Volume, 19, 34-40.

Chakrabarti, M. (1995). Pioneers in philosophy of education. Concept Publishing Company.

Dupuis, A. M., \& Gordon, R. L. (2010). Philosophy of education in historical perspective. University Press of America.

Griffiths, M. (2014). Re-thinking the relevance of philosophy of education for educational policy making. Educational Philosophy and Theory, 46(5), 546-559. 
Hayden, M. J. (2012). What do philosophers of education do? An empirical study of philosophy of education journals. Studies in Philosophy and Education, 31(1), 1-27.

Kumara, S. K. (2016). Meaning, scope \& functions of philosophy of education. International Journal of Social and Economic Research, 6(4), 150-157.

Sahan, H. H., \& Terzi, A. R. (2015). Analyzing the relationship between prospective teachers educational philosophies and their teachinglearning approaches. Educational Research and Reviews, 10(8), 12671275.

Seshadri, C. (2008). Philosophy of education as a knowledge field. New Delhi: National University of Educational Planning and Administration.

Sharma, G. R. (2003). Trends In Contemporary Indian Philosophy Of Education A Critical Evaluation. Atlantic Publishers \& Dist.

Viswanathan, G. (1989). Masks of conquest. New York: Columbia UP. 